\title{
Asynchronous changes of normal lung lobes during respiration based on quantitative computed tomography (CT)
}

\author{
Feihong $\mathrm{Wu}^{1,2 \#}$, Congping Lin $^{3 \#}$, Leqing Chen ${ }^{1,2 \#}$, Jia Huang ${ }^{1,2}$, Wenliang Fan ${ }^{1,2}$, Zhuang Nie ${ }^{1,2}$, \\ Yiwei Zhang ${ }^{3}$, Wanting Li $^{3}$, Jiazheng Wang ${ }^{4}$, Fan Yang ${ }^{1,2}$, Chuansheng Zheng ${ }^{1,2} \wedge$ \\ ${ }^{1}$ Department of Radiology, Union Hospital, Tongji Medical College, Huazhong University of Science and Technology, Wuhan, China; ${ }^{2}$ Hubei \\ Province Key Laboratory of Molecular Imaging, Wuhan, China; ${ }^{3}$ School of Mathematics and Statistics, Center for Mathematical Science, Hubei Key \\ Laboratory of Engineering Modeling and Scientific Computing, Huazhong University of Science and Technology, Wuhan, China; ${ }^{4} \mathrm{MSC}$ Clinical \& \\ Technical Solutions, Philips Healthcare, Beijing, China
}

Contributions: (I) Conception and design: F Yang, C Zheng; (II) Administrative support: C Zheng; (III) Provision of study materials or patients: F Wu, F Yang, C Zheng; (IV) Collection and assembly of data: F Wu, L Chen, W Fan, Z Nie; (V) Data analysis and interpretation: F Wu, C Lin, Y Zhang, W Li, F Yang; (VI) Manuscript writing: All authors; (VII) Final approval of manuscript: All authors.

\#These authors contributed equally to this work.

Correspondence to: Fan Yang; Chuansheng Zheng. Department of Radiology, Union Hospital, Tongji Medical College, Huazhong University of Science and Technology, Wuhan 430022, China. Email: fyang@hust.edu.cn; hqzcsxh@sina.com.

Background: This study aimed to explore the coordinated and independent actions of lung lobes during respiration using quantitative computed tomography (CT) in order to increase our in vivo understanding of pulmonary anatomy.

Methods: Cases for whom test results showed normal pulmonary function tests (PFTs) results, and normal paired inspiratory-expiratory chest CT findings, as assessed by 2 radiologists, were retrospectively included in this study. From the chest CT results, we measured quantitative indices of lung volume (LV) and mean lung density (MLD) for the total lung (TL), left lung (LL), right lung (RL), and 5 lobes in inspiratory and expiratory phases. The differences of these measures between bilateral lungs and among the lobes were evaluated to study whether they were consistent or different during respiration.

Results: A total of 70 cases were included [median age of 49.5 [interquartile range (IQR), 38.0 to 60.3] years; 32 males; 38 females\}. Overall, the inspiratory and expiratory volumes of the LL were smaller than those of the RL (both $\mathrm{P}<0.001)$. For the ventilation workload $(\lambda$, which indicates the ratio of lobar volume to total $L V$ ), the end-expiratory volume ratio $\left(\lambda_{e x}\right)$ of the LL was 0.44 (IQR, 0.43 to 0.46 ), while the endinspiratory volume ratio $\left(\lambda_{\text {in }}\right)$ had risen to 0.46 (IQR, 0.45 to 0.47$)(\mathrm{P}<0.001)$. Comparing the 5 lobes, not all lobes shared the same LV. However, the left lower lobe (LLL) and right lower lobe (RLL) showed some similarities. The $\lambda_{i n-L L L}$ and $\lambda_{i n-R L L}$ was higher than $\lambda_{e x-L L L}$ and $\lambda_{e x-R L L}$, respectively (both $\mathrm{P}<0.001$ ), while the ratios of the other lobes reduced. The pairwise mean absolute difference (PMAD) on $\lambda_{i n}$ and $\lambda_{e x}$ of the bilateral lower lobes was low in inspiration (0.0288) and expiration (0.0346). The MLD of bilateral lower lobes showed consistency in inspiration or in expiration (inspiration: $\mathrm{P}>0.999$; expiration: $\mathrm{P}=0.975$ ). In addition, the PMADs between the right middle lobe (RML) and other lobes were significantly larger than the PMAD between other pairs of lobes in both inspiration and expiration. Beyond that, the expiratory MLD of RML [-789.6 (IQR, -814 to -762.05$) \mathrm{HU}]$ was the lowest among the 5 lobes.

Conclusions: We found that the LL assumes a higher workload during ventilation than it does during respiration. The 5 normal lobes were non-synchronous during respiration and contributed differently to

^ ORCID: Feihong Wu, 0000-0002-2476-4203; Chuansheng Zheng, 0000-0002-2435-1417. 
ventilation. The bilateral lower lobes showed similarities and had a high-ventilation function, while and the LV and MLD of the RML showed the least changes within a respiration cycle.

Keywords: Quantitative computed tomography (CT); pulmonary ventilation function; pulmonary anatomy; respiration

Submitted Mar 30, 2021. Accepted for publication Nov 29, 2021.

doi: 10.21037/qims-21-348

View this article at: https://dx.doi.org/10.21037/qims-21-348

\section{Introduction}

The current understanding of pulmonary anatomy is based on gross morphology dissection, while in vivo studies for lung volume (LV), lung strain, and lung ventilation have mainly been restricted to animal models $(1,2)$. In clinical practice, pulmonary function tests (PFTs), such as spirometry and LV tests, are currently used to show the status and function of the whole lung by inhaling and exhaling repeatedly (3-5). However, PFTs cannot provide information at an individual lobar level.

With the fast development of computed tomography (CT) and image post-processing technology, a chest CT scan can now show the overall and partial pulmonary anatomical and morphological information in a noninvasive, rapid, and objective way. In addition to presenting lesions, CT can also be used as an effective way to identify interlobular fissures and establish normal pulmonary vessel diameters $(6,7)$. Studies have also reported on the use of quantitative $\mathrm{CT}$ values in patients with chronic obstructive pulmonary disease (COPD) and relapsing polychondritis (8-10). Many studies have found that CT quantitative indexes are correlated with clinical lung function indicators, which could indicate emphysema, air trapping, bronchial wall thickening, or airflow limitation (11-13). Pulmonary dual-energy CT (DECT) angiography can even assess pulmonary perfusion (14).

Furthermore, paired exhalation breath-hold and inhalation breath-hold CT or 4 dimensional (4D) CT scans collected during coached breathing can provide an estimate of lung function at a per-voxel level $(15,16)$. Cumulatively, these features make it possible for chest CT to shift from a routine visual evaluation to a detailed quantitative assessment.

The purpose of our study was to demonstrate that normal CT features, at both the total lung (TL) level and lobar level, combined with quantitative CT indices, can be used to explore the coordination and differences among lung lobes during inspiration and expiration. In doing so, we aimed to deepen the in vivo understanding of pulmonary anatomy and create a baseline for quantitative CT in respiratory disease research and clinical applications.

\section{Methods}

\section{Cases}

The study was conducted in accordance with the Declaration of Helsinki (as revised in 2013). The Union Hospital, Tongji Medical College, Huazhong University of Science and Technology Institutional Review Board approved the study (No. 0271-01) and waived the requirement for informed consent due to the retrospective nature of the analysis. We retrospectively collected the records of patients who had attended our hospital for health examination from April 2020 to October 2020 by screening in Picture Archiving and Communication Systems (PACS) and Outpatient system. The inclusion criteria were as follows: (I) PFTs results were normal according to Chinese PFTs report specifications issued by the Chinese Medical Doctor Association (17); and (II) there were paired inspiratory-expiratory chest CT scans with normal imaging findings (no abnormal pulmonary parenchymal or airway process was present) as assessed by 2 radiologists (FW and FY with 5 and 27 years of thoracic radiology experience, respectively). The exclusion criteria were as follows: (I) acute and chronic diseases of other organ systems; (II) incomplete inspiration or expiration during the CT scan; and/or (III) the quality of the CT image did not meet the post-processing requirements (e.g., significant motion artifacts, congenital lobar variation).

\section{CT scan}

Prior to screening, all cases were trained in breathing and instructed to perform multiple deep inhale-breath- 


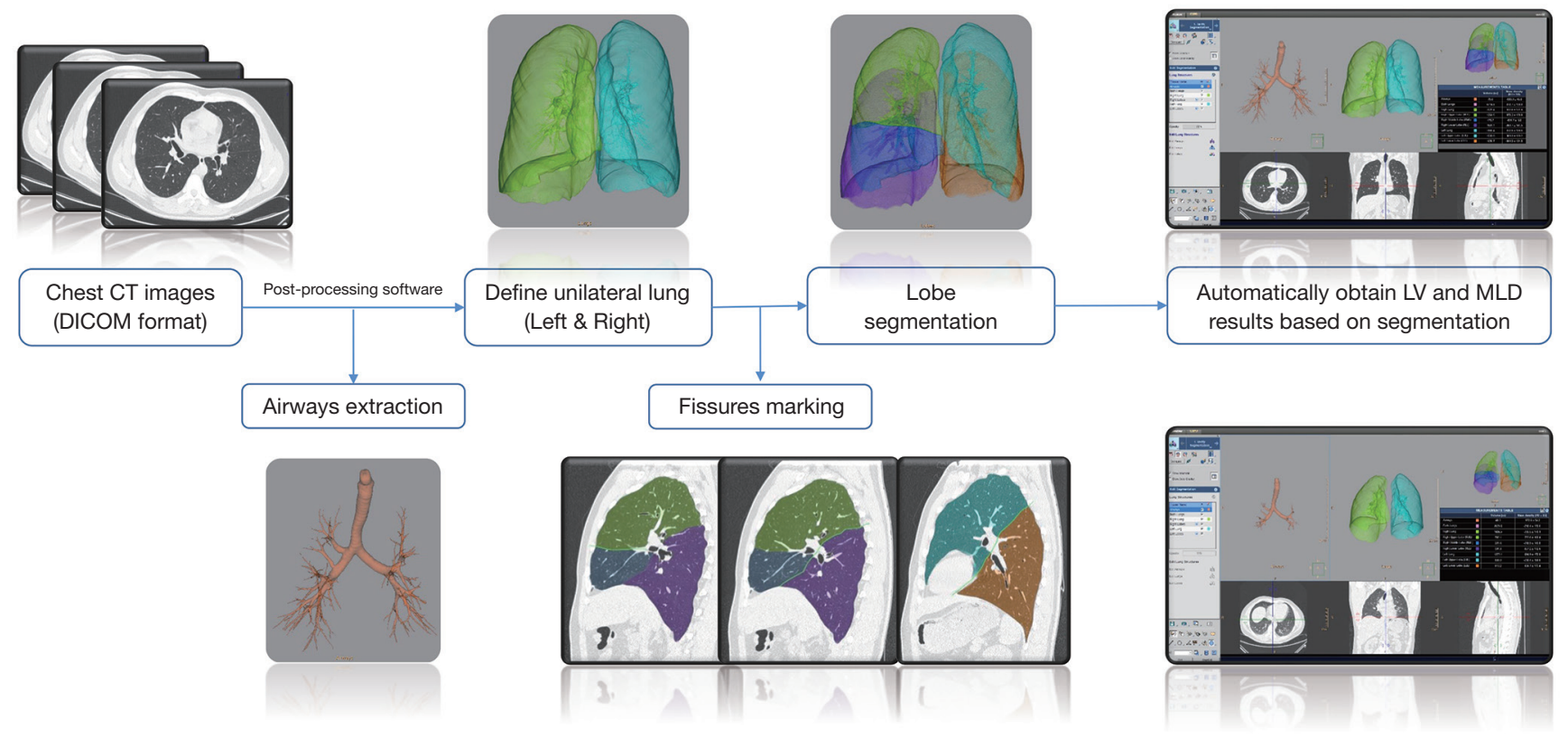

Figure 1 Flow chart of obtaining quantitative CT results by imaging post-processing software. CT, computed tomography; DICOM, digital imaging and communications in medicine; LV, lung volume; MLD, mean lung density.

hold and deep exhale-breath-hold cycles by experienced technicians. Then, the cases underwent CT scanning and paired inspiratory-expiratory chest $\mathrm{CT}$ scans in the supine position (IQon Spectral CT, Philips Healthcare, Best, The Netherlands). The scanning range was from the apex to the base of the chest, and the scanning direction was head-tofoot. The scanning conditions were as follows: fixed tube voltage of $120 \mathrm{kV}$; 3D tube current automatic modulation technology; pitch of 0.984 ; and detector at $64 \times 0.625 \mathrm{~mm}$.

\section{Quantitative image analysis}

The CT images in digital imaging communications in medicine (DICOM) format were sent to the Philips IntelliSpace Portal post-processing workstation. Then, 2 radiologists (FY and $\mathrm{FW}$ ) with 27 and 5 years of experience, respectively, performed the measurements described below using the COPD analysis software. Any disagreements were resolved through discussion to reach a consensus. First, the trachea-bronchial tree was defined and automatically extracted out in the recognition of the respiratory system based on CT images, and then the left lung (LL) and right lung (RL) contours were identified. Second, the 5 lobes [left upper lobe (LUL), left lower lobe (LLL), right upper lobe (RUL), right middle lobe (RML), and right lower lobe (RLL)] were automatically segmented by identifying the interlobular fissures, and manual corrections were performed when inaccurate segmentation was recognized by the software. The flow chart of the post-processing is shown in Figure 1. The following data were then automatically generated for the inspiratory and expiratory phases: the $\mathrm{LV}(\mathrm{mL})$ and mean lung density (MLD; HU) of the TL, LL, RL, and the 5 lobes. To better explore the coordination and difference among the lobes in the respiratory process, we calculated some extra parameters according to the following formulae:

$$
\Delta L V_{a}=L V_{\text {in }-a}-L V_{\text {ex-a }}
$$

$\Delta \mathrm{LV}$ represents lung (or lobe) volume change during respiration; $a$ indicates the TL, LL, RL, or one of the 5 lobes; $L V_{\text {in }}$ represents inspiratory lung (or lobe) volume; and $L V_{\mathrm{ex}}$ represents expiratory lung (or lobe) volume.

$$
V V R=\frac{\Delta L V_{a}}{\Delta L V_{T L}}
$$

VVR represents the ventilation volume ratio (the ratio of lobar to total LV change); $a$ indicates the LL, RL, or one of the 5 lobes; $\Delta \mathrm{LV}$ indicates the volume change during respiration; and $\Delta \mathrm{LV}_{\mathrm{TL}}$ indicates the total $\mathrm{LV}$ change during respiration. 


$$
\triangle M L D_{a}=M L D_{e x-a}-M L D_{i n-a}
$$

$\triangle M L D$ represents mean lung (or lobe) density change during respiration; $a$ indicates the TL, LL, RL, or one of the 5 lobes; $\mathrm{MLD}_{\mathrm{ex}}$ represents expiratory mean lung (or lobe) density; and $\mathrm{MLD}_{\text {in }}$ represents inspiratory mean lung (or lobe) density.

$$
\lambda_{i n-a}=\frac{L V_{i n-a}}{L V_{i n-T L}}
$$

$\lambda_{\text {in }}$ indicates the lobe volume ratio in inspiratory phase; $a$ indicates the LL, RL, or one of the 5 lobes; and $\mathrm{LV}_{\mathrm{in}-\mathrm{TL}}$ means the inspiratory total $\mathrm{LV}$.

$$
\lambda_{e x-a}=\frac{L V_{e x-a}}{L V_{e x-T L}}
$$

$\lambda_{e x}$ indicates the lobe volume ratio in expiratory phase; $a$ indicates the LL, RL, or one of the 5 lobes; and $\mathrm{LV}_{\text {ex-TL }}$ means the expiratory total LV.

We evaluated interlobar differences in the volume ratio of each lobe compared to the inspiratory or expiratory TL by using the pairwise mean absolute difference (PMAD) on $\lambda_{\text {in }}$ and $\lambda_{e x}$ to calculate the difference between a pair of lobes, averaged among the whole cohort. This was similar to the mean absolute distance (MAD), which measures the average of the absolute signed distance between 2 contours (18-20). The PMAD of the inspiratory or expiratory phase between two lobes was calculated as follows:

$$
\operatorname{PMAD}\left(a_{1}, a_{2}\right)=\frac{1}{n} \sum_{i=1}^{n}\left|\lambda_{1, i}-\lambda_{2, i}\right|
$$

$a_{1}$ and $a_{2}$ were indicators for the 2 lobes needed to be compared; $\lambda_{1, i}$ and $\lambda_{2, i}$ were calculated by Eq. [4] or Eq. [5] in the corresponding phase; $i$ referred to the case under study; and $n$ was the sample size. A high value of PMAD indicated a statistically large difference in the volume ratio between the pair, whereas a low PMAD value indicated a similar volume ratio between the pair.

\section{Statistical analysis}

Data analysis was performed using SPSS statistics (version 26.0; IBM Corp., Armonk, NY, USA) and GraphPad Prism 9 (GraphPad Software Inc., La Jolla, CA, USA). Analysis of the PMAD in the volume ratio was performed using MATLAB (R2020a; MathWorks, Natick, MA, USA). Continuous variables from the quantitative CT results were expressed as the median and interquartile range (IQR) and were compared between inspiratory and expiratory phases or between bilateral lungs using the Wilcoxon signedrank test. Pairwise comparisons of LV and MLD between the 5 lobes in inspiration and expiration were performed with the Friedman test in a post hoc analysis. Stepwise multivariable linear regression analysis was used to explore the relationship between baseline demographic data (gender, age, height, and weight, for which gender was assigned as 1, male; 2, female) and the quantitative CT results $\left(\mathrm{LV}_{\mathrm{ex}}\right.$, $M_{\text {ex }}, \mathrm{LV}_{\text {in }}$, and $\mathrm{MLD}_{\text {in }}$ ), with an entry criterion of $\mathrm{P}<0.05$ and a removal criterion of $\mathrm{P}>0.10$. The $\mathrm{P}$ values $<0.05$ were considered statistically significant. When necessary, Bonferroni correction was used for multiple comparisons.

\section{Results}

\section{Study cases}

A total of 81 cases with normal PFTs results and paired inspiratory-expiratory chest CT images were retrospectively enrolled. Among them, 7 cases were excluded for poor image quality that could not meet the post-processing requirements, 3 cases were excluded for abnormal chest CT image findings (1 had chronic tuberculosis, 1 had chronic pulmonary inflammation, and 1 had emphysema), and 1 case was excluded because the patient's costophrenic angle exceeded the scanning range in the inspiratory phase. Finally, 70 cases were included in this study, with a median age of 49.5 (IQR, 38.0 to 60.3 ) years, including 32 males with a median age of 47 (IQR, 38.3 to 62.0) years, and 38 females with a median age of 51.5 (IQR, 38.0 to 60.3) years. There was no significant difference in the age of males and females included in the study $(\mathrm{P}=0.911)$.

\section{Comparison of quantitative indices among lobes in inspiration or expiration}

From these 70 cases, for the $\mathrm{LV}$ and MLD of the TL as measured in CT, the $\mathrm{LV}_{\text {in-TL }}$ was 4,509.19 (IQR, 4,039.79 to $5,593.61) \mathrm{mL}$, the $\mathrm{LV}_{\text {ex-TL }}$ was $2,255.3$ (IQR, 1,950.73 to $2,650.96) \mathrm{mL}$, the $\mathrm{MLD}_{\text {in-TL }}$ was -861.8 (IQR, -868.85 to -842.13$) \mathrm{HU}$, and the $\mathrm{MLD}_{\text {ex-TL }}$ was -712.6 (IQR, -746.68 to -687.85$) \mathrm{HU}$. The LV and MLD in inspiration or expiration of the bilateral lung and each lobe are shown in Table 1, and the comparisons among lobes are shown in Figure 2. Compared with the inspiratory phase, $L V_{\text {ex }}$ decreased and $M L D_{e x}$ increased in the bilateral lung and in the 5 lung lobes (all $\mathrm{P}<0.001$ ).

Comparing the LL to the RL, $\mathrm{LV}_{\text {in-LL }}[2,068.99$ (IQR, 
Table $1 \mathrm{LV}$ and MLD measured by quantitative CT in all cases

\begin{tabular}{|c|c|c|c|c|}
\hline Indices & Inspiration & Expiration & Change $(\Delta)$ & $P$ value \\
\hline $\mathrm{TL}$ & $4,509.19(4,039.79,5,593.61)$ & $2,255.3(1,950.73,2,650.96)$ & $2,305.88(1,979.38,2,843.55)$ & $<0.001$ \\
\hline LL & $2,068.99(1,860.2,2,620.94)$ & 1,006.86 (842.83, 1,199.42) & $1,097.1(942.59,1,357.28)$ & $<0.001$ \\
\hline $\mathrm{RL}$ & $2,449.42(2,179.17,2,912.08)$ & $1,247.05(1,100.12,1,491.47)$ & $1,186.68(1,017.75,1,513.99)$ & $<0.001$ \\
\hline LLL & $1,041.64(885.77,1,290.62)$ & $444.45(350.03,534.3)$ & $604.35(503.8,727.64)$ & $<0.001$ \\
\hline RUL & $935.44(782.77,1,094.84)$ & $488.2(418.63,601.77)$ & $407.07(307.03,492.42)$ & $<0.001$ \\
\hline RML & $407.3(363.11,495.82)$ & $259.51(223.23,310.57)$ & $152.53(109.92,191.56)$ & $<0.001$ \\
\hline RLL & 1,168.89 (999.79, 1,368.05) & $492.03(430.68,594.28)$ & $668.99(548.22,773.07)$ & $<0.001$ \\
\hline LL & $-859.8(-870.4,-843.28)$ & $-696.5(-739.9,-668.28)$ & $161.25(118.53,186.98)$ & $<0.001$ \\
\hline $\mathrm{RL}$ & $-861.2(-869.85,-841.65)$ & $-724.85(-751.93,-694.98)$ & $134.55(107.3,158.8)$ & $<0.001$ \\
\hline LUL & $-867.85(-877.88,-850.48)$ & $-742.35(-774.53,-711.68)$ & $123.15(86.7,151.33)$ & $<0.001$ \\
\hline LLL & $-849.15(-863.83,-829.55)$ & $-640.65(-685.65,-604.18)$ & $207.9(160.83,238.45)$ & $<0.001$ \\
\hline RUL & $-864.3(-874.63,-850.75)$ & $-749.95(-772.43,-712.65)$ & $108.9(90.43,152.3)$ & $<0.001$ \\
\hline RML & $-873.15(-884.33,-860.38)$ & $-789.6(-814,-762.05)$ & $77.6(61.73,104.88)$ & $<0.001$ \\
\hline RLL & $-851(-861.93,-832.48)$ & $-659.75(-698.5,-629.08)$ & $187(150.95,216.83)$ & $<0.001$ \\
\hline
\end{tabular}

Data are median and IQR. $P$ values for comparison of LV or MLD in the inspiratory and the expiratory phase were analyzed using the Wilcoxon signed-rank test. LV, lung volume; MLD, mean lung density; CT, computed tomography; TL, total lung; LL, left lung; RL, right lung; LUL, left upper lobe; LLL, left lower lobe; RUL, right upper lobe; RML, right middle lobe; RLL, right lower lobe; IQR, interquartile range.

$1,860.2$ to $2,620.94) \mathrm{mL}]$ and $\mathrm{LV}_{\text {ex-LL }}[1,006.86$ (IQR, 842.83 to $1,199.42) \mathrm{mL}]$ were both lower than $\mathrm{LV}_{\text {in-RL }}[2,449.42$ (IQR, 2,179.17 to $2,912.08) \mathrm{mL}]$ and $\mathrm{LV}_{\text {ex-RL }}[1,247.05$ (IQR, $1,100.12$ to $1,491.47) \mathrm{mL}$, both $\mathrm{P}<0.0001$, Figure $2 A$. However, there was no difference in the $\mathrm{MLD}_{\text {in }}$ of the bilateral lung $\left[\mathrm{MLD}_{\text {in-LL }}\right.$ vs. MLD $\mathrm{in}_{\mathrm{in}-\mathrm{LL}}:-859.8$ (IQR, -870.4 to -843.28$) \mathrm{HU}$ vs. -861.2 (IQR, -869.85 to -841.65$) \mathrm{HU}$, $\mathrm{P}=0.1118]$ while the $M L D_{\text {ex-LL }}$ was higher than $M L D_{\text {ex-RL }}$ [-696.5 (IQR, -739.9 to -668.28 ) HU vs. -724.85 (IQR, -751.93 to -694.98$) \mathrm{HU}, \mathrm{P}<0.0001$, Figure $2 D]$.

Comparing the 5 lobes, the volumes during inspiration or expiration were not all the same among lobes (Figure 2B,2C); however, the MLD of the bilateral upper lobes (LUL and RUL) and the bilateral lower lobes (LLL and RLL) showed no difference in inspiration or expiration (inspiration: $\mathrm{P}=0.480, \mathrm{P}>0.999$, respectively; expiration:
$\mathrm{P}>0.999, \mathrm{P}=0.975$, respectively; Figure $2 E, 2 F)$. As the smallest lobe in volume, the RML showed no difference in $M D_{\text {in }}$ compared to the LUL [MLD $_{\text {in-RML }}$ vs. MLD ${ }_{\text {in-LUL }}$ : -873.15 (IQR, -884.33 to -860.38 ) HU vs. -867.85 (IQR, -877.88 to -850.48$) \mathrm{HU}, \mathrm{P}=0.081$ ], while the RML demonstrated the lowest $\mathrm{MLD}_{\mathrm{ex}}\left[\mathrm{MLD}_{\mathrm{ex}-\mathrm{RML}}\right.$ : $-789.6(\mathrm{IQR}$, -814 to -762.05$) \mathrm{HU}$ ] among the 5 lobes.

\section{Comparison of quantitative indices among lobes during respiration}

For the volume change and MLD change of the TL as measured with CT (Table 1), the $\Delta \mathrm{LV}_{\mathrm{TL}}$ was 2,305.88 (IQR, $1,979.38$ to $2,843.55) \mathrm{mL}$, and the $\Delta \mathrm{MLD}_{\mathrm{TL}}$ was 146.25 (IQR, 112.85 to 170.43 ) HU.

The ratios relative to volume $\left(\Delta \mathrm{LV}, \mathrm{VVR}, \lambda_{i n}, \lambda_{e x}\right.$, and 
A Bilateral lung volume during respiration $B$
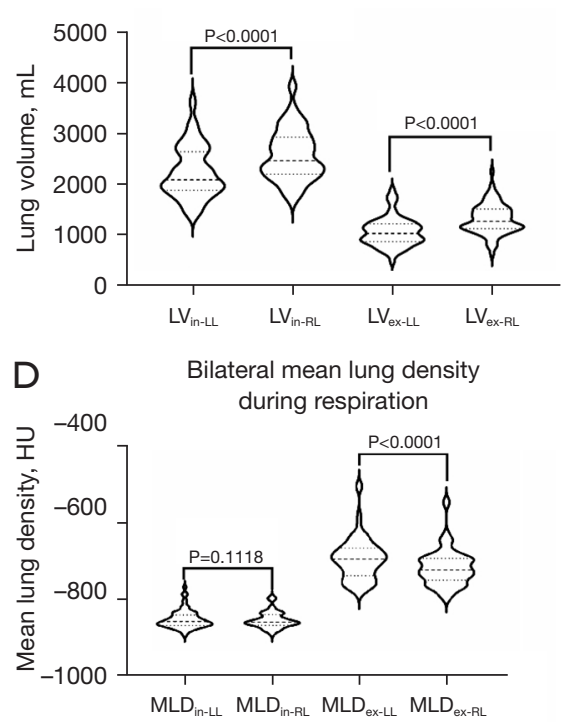
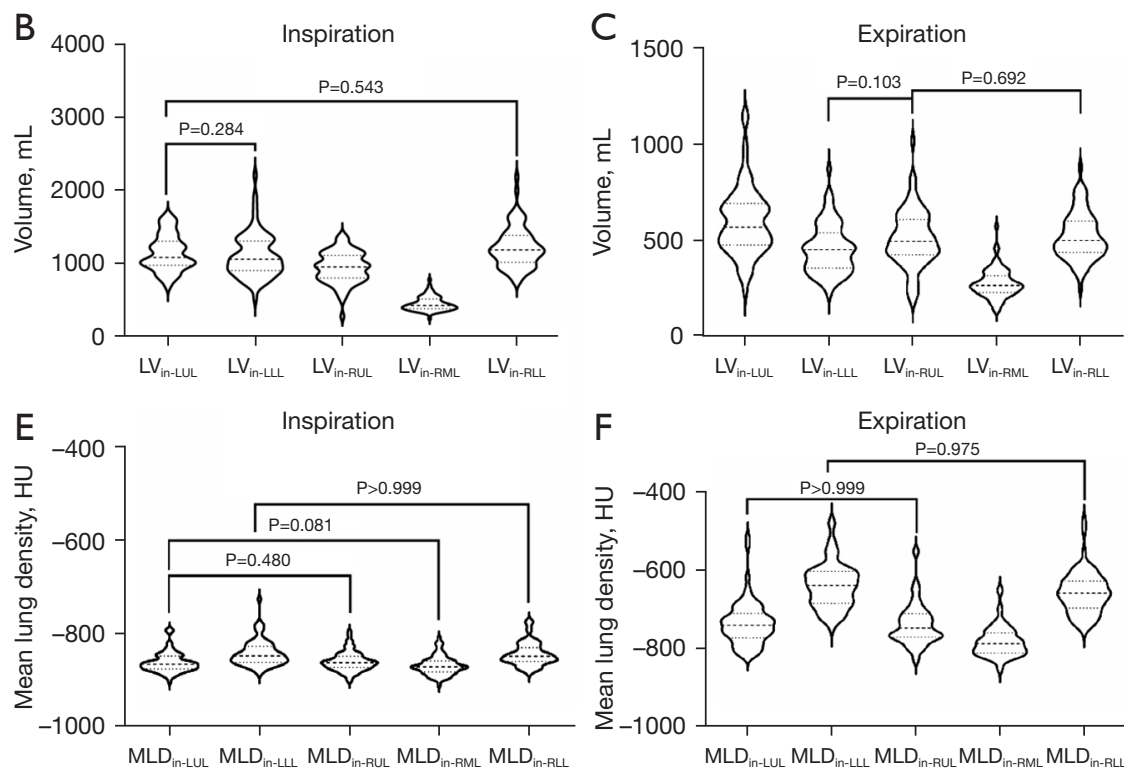

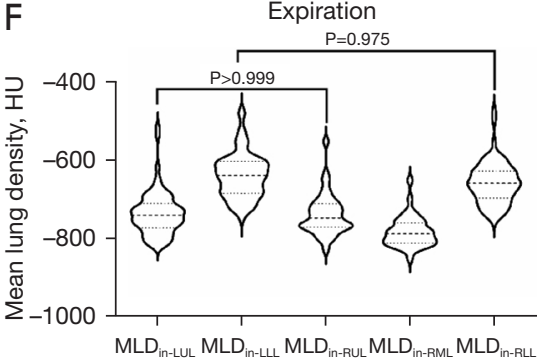

Figure 2 Volume and MLD of the bilateral lung and 5 lobes during inspiration and expiration. (A) Comparison of the volume of LL and RL in inspiration and expiration. (B) Comparison of the inspiratory volume among the 5 lobes. (C) Comparison of the expiratory volume among 5 lobes. (D) Comparison of the MLD of the LL and RL in inspiration and expiration. (E) Comparison of the inspiratory MLD among the 5 lobes. (F) Comparison of the expiratory MLD among the 5 lobes. $L V_{\text {in }}$, lung volume in the inspiratory phase; LL, left lung; RL, right lung; $\mathrm{LV}_{\mathrm{ex}}$, lung volume in the expiratory phase; LUL, left upper lobe; LLL, left lower lobe; RUL, right upper lobe; RML, right middle lobe; RLL, right lower lobe; $M L D_{\text {in }}$, mean lung density in the inspiratory phase; $M L D_{\text {ex }}$, mean lung density in the expiratory phase; MLD, mean lung density.

Table 2 Ratios relative to volume during respiration

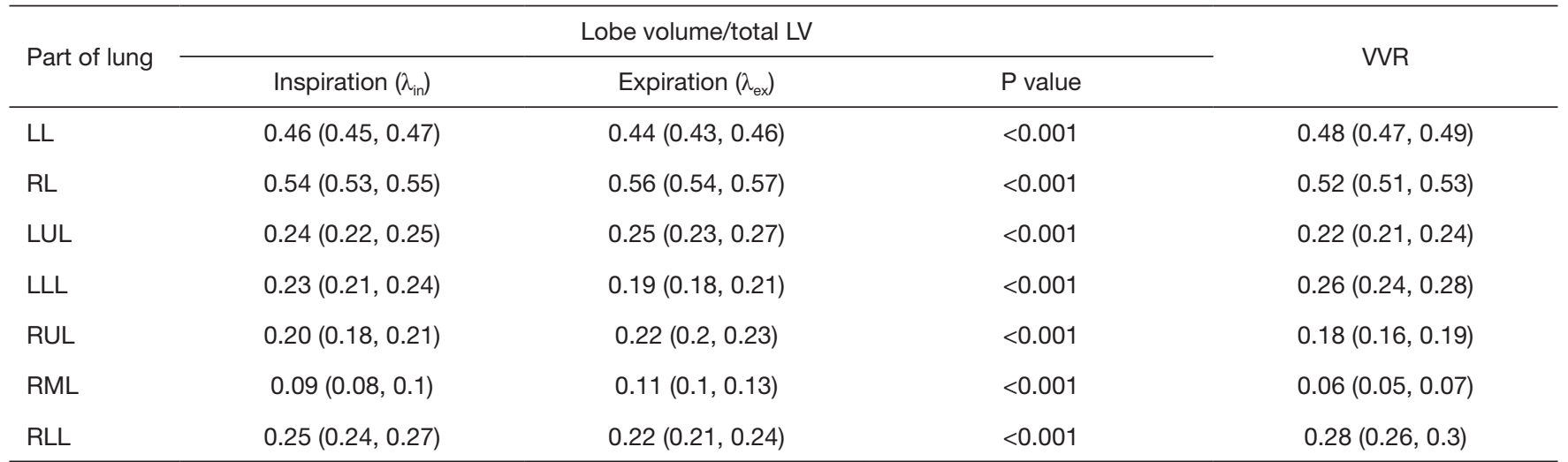

Data are median and IQR. P values for ratio comparison in the inspiratory and the expiratory phase were analyzed using the Wilcoxon signed-rank test. VVR indicates each part's volume change/total LV change. LV, lung volume; VVR, ventilation volume ratio; LL, left lung; RL, right lung; LUL, left upper lobe; LLL, left lower lobe; RUL, right upper lobe; RML, right middle lobe; RLL, right lower lobe; IQR, interquartile range.

PMAD) based on $L V_{\text {in }}$ and $L V_{\text {ex }}$ are shown in Table 2, Figures 3,4. From the perspective of the proportion of each part to the TL $\left(\lambda_{i n}\right.$ and $\lambda_{e x}$ ), the end-expiratory proportion of the LL $\left(\lambda_{e x-L L}\right)$ was 0.44 (IQR, 0.43 to 0.46 ), while the endinspiratory ratio $\left(\lambda_{i n-L L}\right)$ had risen to 0.46 (IQR, 0.45 to 0.47 ; $\mathrm{P}<0.001)$. This indicated that the LL played a larger role in 
A

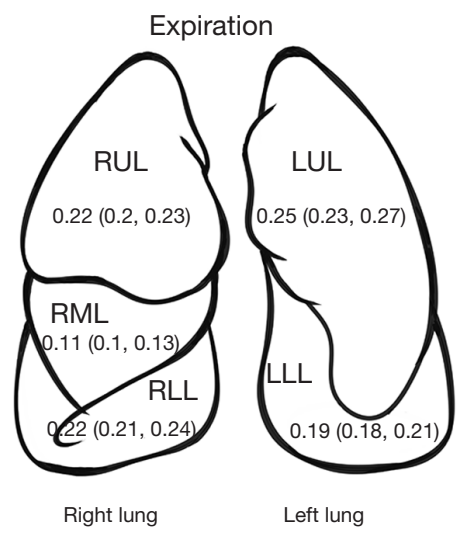

B

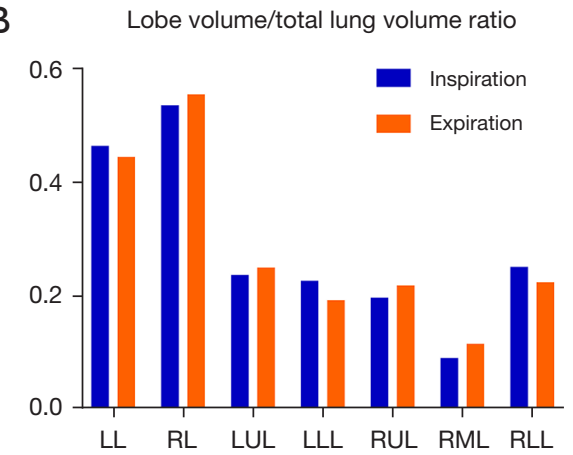

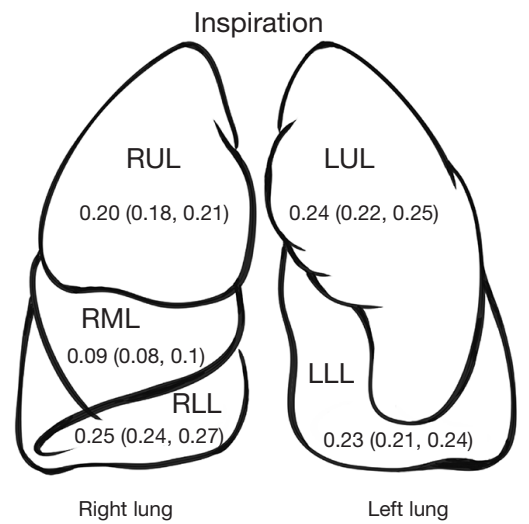

C

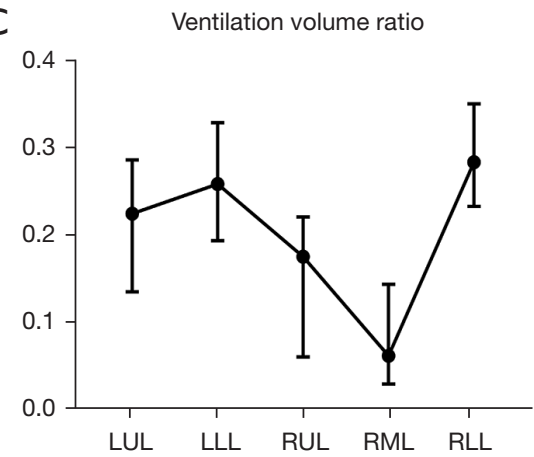

Figure 3 Ratios of volume derived by $L V_{\text {in }}$ and $L V_{\text {ex }}$. $(A, B)$ The ratio of each lobe volume to the total $L V$ in the inspiration $\left(\lambda_{i n}\right)$ and expiration $\left(\lambda_{e x}\right)$. (C) The VVR, which indicates the ratio of the volume change of each lobe compared with the total LV change. RUL, right upper lobe; RML, right middle lobe; RLL, right lower lobe; LUL, left upper lobe; LLL, left lower lobe; LL, left lung; RL, right lung; $L V_{\text {in }}$, inspiratory lung (or lobe) volume; $\mathrm{LV}_{\mathrm{ex}}$, expiratory lung (or lobe) volume; VVR, ventilation volume ratio.

ventilation than its own volume ratio would be assumed take to TL during respiration.

As for the 5 lobes, the $\lambda_{\text {in-LLL }}$ [0.23 (IQR, 0.21 to 0.24)] and $\lambda_{\text {in-RLL }}[0.25$ (IQR, 0.24 to 0.27 )] were higher than $\lambda_{\text {ex-LLL }}\left[0.19\right.$ (IQR, 0.18 to 0.21 )] and $\lambda_{\text {ex-RLL }}$ [0.22 (IQR, 0.21 to 0.24 )], respectively (both $\mathrm{P}<0.001$ ), while the ratios of the other lobes reduced. This suggested that the bilateral lower lobes were responsible for more ventilation than it should proportionately take. On the other hand, both the $\mathrm{PMAD}_{\text {(LLL-RLL) }}$ were low during inspiration (0.0288) and expiration (0.0346), indicating that the volume of the bilateral lower lobe was similar during both phases of respiration.

In addition, results showed larger PMAD values of RML compared to other lobes, indicating that the differences between the RML and other lobes were much larger than the differences in other pairs in both inspiration and expiration (Figure 4, in which the color bar indicates the PMAD for each pair). The multivariable linear regression analysis of the baseline demographic factors (gender, age, height, and weight) that related to the $L V_{\text {in }}$ and $M L D_{\text {in }}$ of each lobe showed that weight was only related to $\mathrm{LV}_{\text {in-RML }}$ and gender was only related to $\mathrm{MLD}_{\text {in-RML }}$ (Table 3).

\section{Discussion}

This study involved anatomical research to quantitatively describe the respiratory status of healthy lungs in vivo. Previous studies about quantitative CT on healthy participants have focused on the relationship between quantitative indices of different CT threshold ranges and clinical pulmonary function indicators, or explored the differences between different groups (e.g., gender, smoking history) (21-25). Our study used the quantitative values derived by chest CT to demonstrate the baseline CT characteristics from the TL to lobar level in inspiration and expiration of healthy people, and to further explore the 
A PMAD matrix of lobes in inspiration

\begin{tabular}{|c|c|c|c|c|c|}
\hline & LUL & LLL & RUL & RML & RLL \\
\hline LUL & 0.0000 & 0.0313 & 0.0433 & 0.1450 & 0.0318 \\
\hline LLL & 0.0313 & 0.0000 & 0.0427 & 0.1348 & 0.0288 \\
\hline RUL & 0.0433 & 0.0427 & 0.0000 & 0.1064 & 0.0605 \\
\hline RML & 0.1450 & 0.1348 & 0.1064 & 0.0000 & 0.1609 \\
\hline RLL & 0.0318 & 0.0288 & 0.0605 & 0.1609 & 0.0000 \\
\hline
\end{tabular}

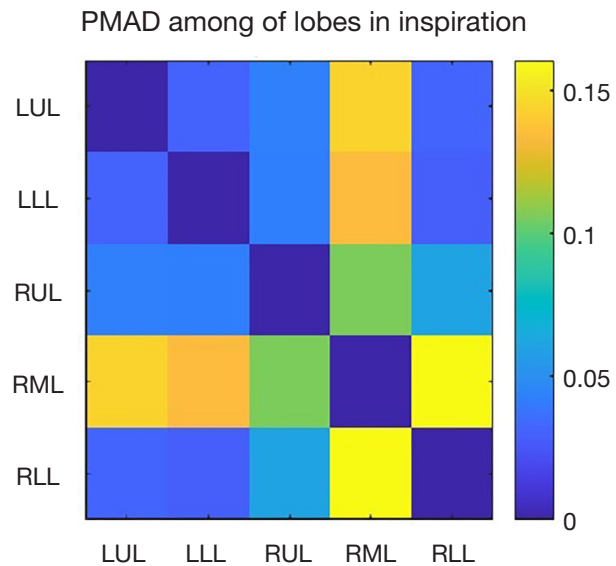

B

PMAD matrix of lobes in expiration

\begin{tabular}{c|c|c|c|c|c|}
\multicolumn{1}{c}{ LUL } & \multicolumn{1}{c}{ LLL } & \multicolumn{1}{c}{ RUL } & \multicolumn{1}{c}{ RML } & \multicolumn{1}{c}{ RLL } \\
\cline { 2 - 6 } LUL & 0.0000 & 0.0596 & 0.0398 & 0.1335 & 0.0402 \\
\cline { 2 - 6 } & & & & & \\
\hline \multirow{3}{*}{ LLL } & 0.0596 & 0.0000 & 0.0443 & 0.0756 & 0.0346 \\
\cline { 2 - 6 } RUL & 0.0398 & 0.0443 & 0.0000 & 0.1044 & 0.0336 \\
\cline { 2 - 6 } RML & 0.1335 & 0.0756 & 0.1044 & 0.0000 & 0.1055 \\
\cline { 2 - 6 } RLL & 0.0402 & 0.0346 & 0.0336 & 0.1055 & 0.0000 \\
\hline
\end{tabular}

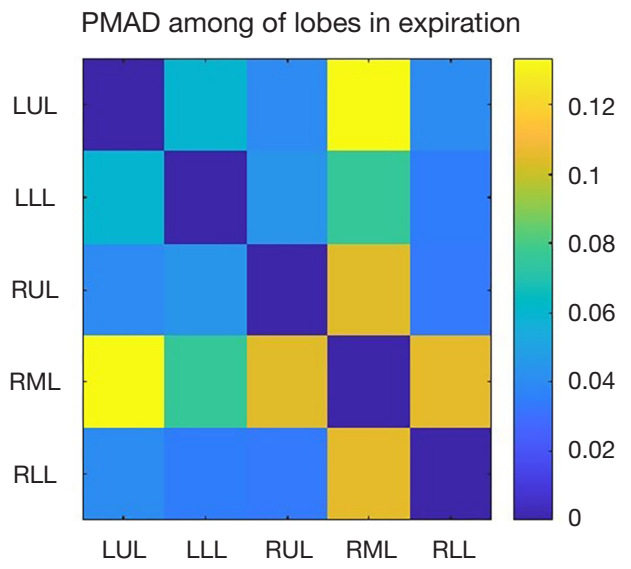

Figure 4 The PMAD of each lobe in the inspiration and expiration. (A) The PMAD value matrix of the inspiratory phase between two lobes (left figure) and the corresponding visualization (right figure). (B) The PMAD value matrix of the expiratory phase between two lobes (left figure) and the corresponding visualization (right figure). The smaller the value, the bluer the color, which represents the smaller the difference between the two lobes. Conversely, the larger the value, the yellower the color, which represents the greater the difference between the two lobes. PMAD, pairwise mean absolute difference; LUL, left upper lobe; LLL, left lower lobe; RUL, right upper lobe; RML, right middle lobe; RLL, right lower lobe.

coordination and difference in inspiration-expiration cycles both for the TL and for each of the 5 lobes.

From the perspective of the TL, the $\mathrm{LV}_{\text {in-TL }}$ was measured at 4,509.19 (IQR, 4,039.79 to $5,593.61$ ) $\mathrm{mL}$, which was close to the 4,423 (IQR, 3,614 to 5,294 ) $\mathrm{mL}$ obtained using quantitative CT in the Chinese normal LV reported by Cheng et al. (26). The $\Delta \mathrm{LV}$ was $2,305.88$ (IQR, $1,979.38$ to $2,843.55$ ) $\mathrm{mL}$, which was lower than the normal forced vital capacity (FVC; the maximal volume of air exhaled with maximally forced effort from a maximal inspiration) of the Chinese clinical
PFTs value reported by the China Pulmonary Health Study Group (mean male FVC: 4,300 mL; mean female FVC: $3,000 \mathrm{~mL})(4,27)$. We speculated that this observation might be due to the following reasons: (I) FVC and the CT measurements in our study scope involved different breathing patterns. The FVC requires repetitive maximal inspiration to the total lung capacity (TLC) level, followed by fast and complete exhalation to the end of test (4). In comparison, the paired inspiratory-expiratory chest CT scan only acquires the normal deep-breathing pattern. (II) 
Table 3 Multivariate linear regression analyses of inspiration LV or MLD predicted by the expiration

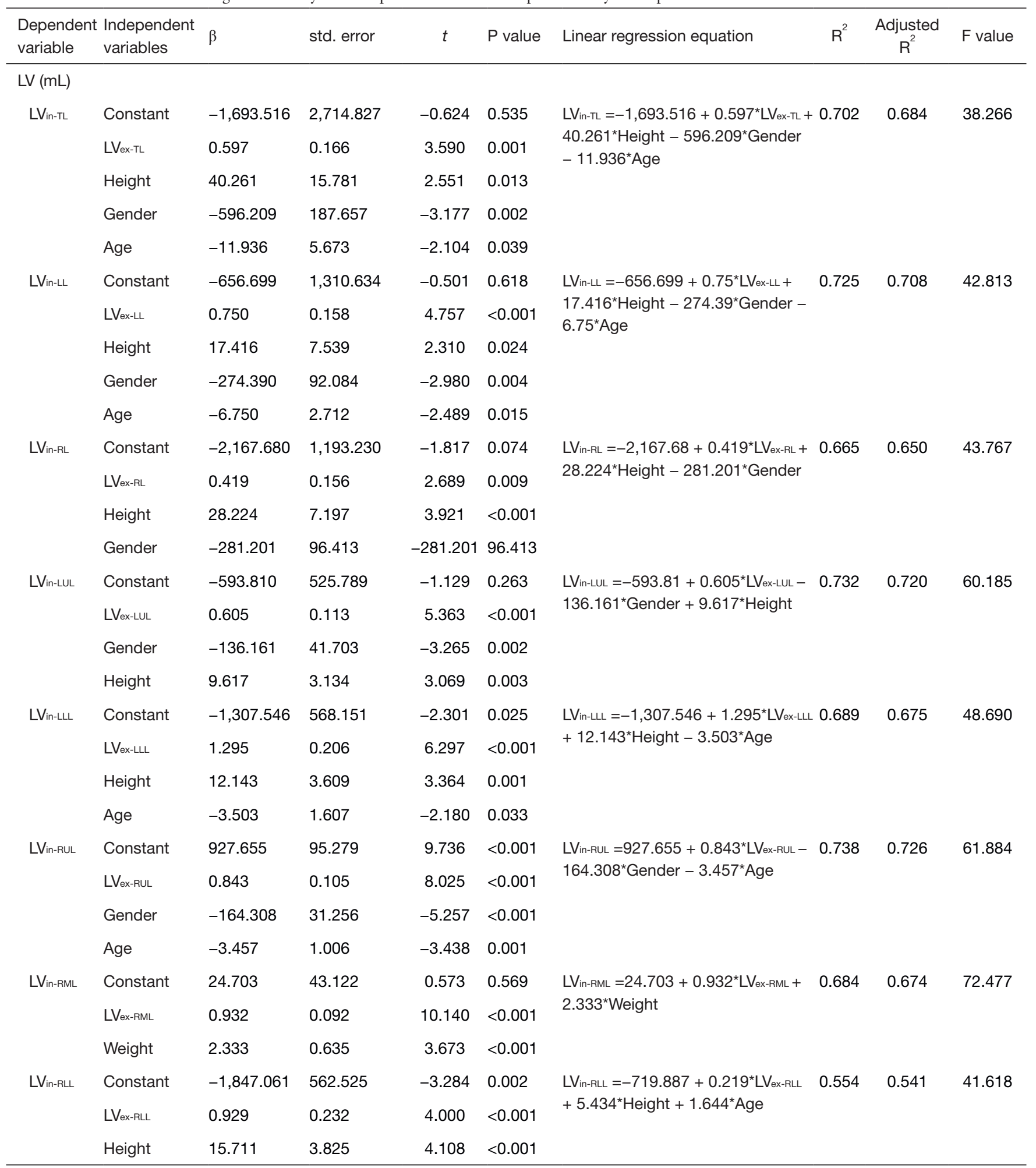

Table 3 (continued) 
Table 3 (continued)

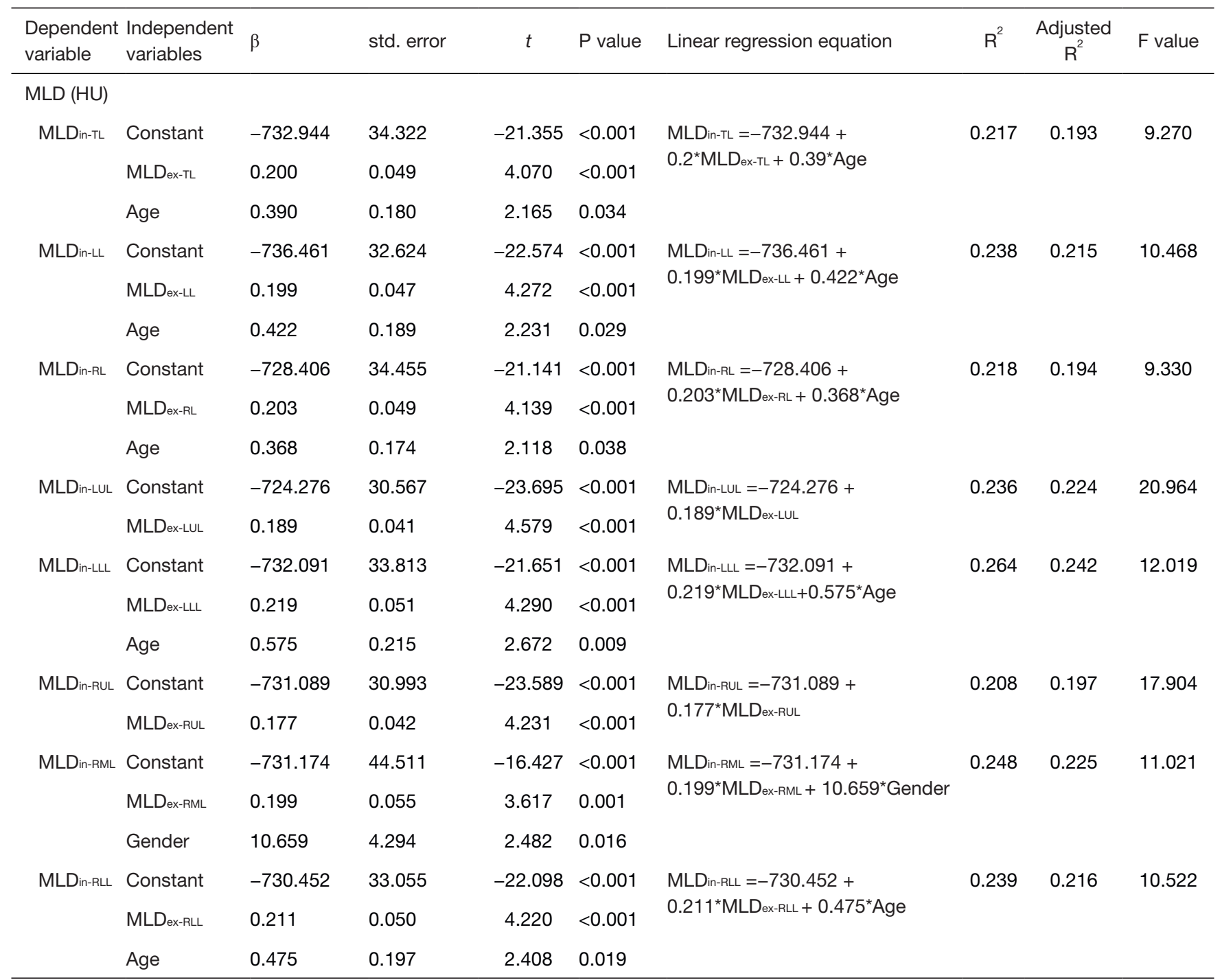

Stepwise multivariable linear regression analysis was used to explore the relationship between baseline demographic data (gender, age, height, and weight, for which gender was assigned as 1, male; 2, female) and the quantitative CT results $\left(\operatorname{LV}_{\text {ex }}, M_{L D}\right.$,,$L_{\text {in }}$, and $\left.M L D_{\text {in }}\right)$, with an entry criterion of $\mathrm{P}<0.05$ and a removal criterion of $\mathrm{P}>0.10$. $\mathrm{P}$ values $<0.05$ were considered statistically significant. $L V$, lung volume; MLD, mean lung density; $\mathrm{LV}_{\text {in }}$, lung volume in the inspiratory phase; $T L$, total lung; $\mathrm{LV}_{\mathrm{ex}}$, lung volume in the expiratory phase; $L L$, left lung; $\mathrm{RL}$, right lung; LUL, left upper lobe; LLL, left lower lobe; RUL, right upper lobe; RML, right middle lobe; RLL, right lower lobe; $M L D_{\text {in }}$, mean lung density in the inspiratory phase; $\mathrm{MLD}_{\mathrm{ex}}$, mean lung density in the exspiratory phase; CT, computed tomography.

The examination position is different. FVC is measured in the seated position, while the CT scan is conducted in the supine position. Mendes et al. (28) reported that the LV in the seated position was greater than that in the supine position.

Comparing between the bilateral lungs, both the inspiratory and expiratory volume of the LL were smaller than that of the RL, which may be due to the location of the heart in the left thorax. The change in lobar volume to the total $L V$ ratio in pre- and post-breath $\left(\lambda_{i n}\right.$ and $\left.\lambda_{e x}\right)$ can be used to observe the ventilation workload of different pulmonary parts. The median ratio of the LL volume to the total LV in the expiratory phase $\left(\lambda_{e x-L L}\right)$ was 0.44 . If the bilateral lung shared the same ventilation work 
according to the proportion of the volume, the ratio at end-inspiration $\left(\lambda_{i n-L L}\right)$ should also be 0.44 , but the actual ratio had increased to $0.46(\mathrm{P}<0.001)$. This indicated that the LL had completed more ventilation work than its proportionate share during respiration. Furthermore, we also corroborated this finding from the MLD results (Figure 2D), in which the density of any volume of the lung may be considered a combination of "air" and "pulmonary tissue" (29). Therefore, the volume change caused by lung expansion and contraction during the breathing process will cause changes in the composition ratio of these 2 compartments, which is also shown in the MLD value. Compared with the RL, the $M_{\text {L }} D_{\text {ex LL }}$ was higher than $M_{L} D_{\text {ex-RL }}$, but there was no difference between $M L D_{\text {in-LL }}$ and $M L D_{\text {in-RL }}$ at the end of inspiration when air was inhaled (the air presented as very low density on the CT image). All of the above indicated that the LL had a higher workload during breathing despite its smaller volume. The clinical implication of this is that it may be beneficial to reduce the radiation doses given to the LL during function avoidance radiation therapy, as it has been shown that high-functioning tissues are more susceptible to radiation damage than low-functioning tissues $(30,31)$.

The inspiratory and expiratory LV and MLD of the 5 lobes were not all the same, but we found that bilateral lower lobes were consistent in some respects. First, there were no significant differences between $M L D_{\text {in-LLL }}$ and $M L D_{\text {in-RLL }}(P>0.999)$, and between $M_{\text {ex-LLL }}$ and $\operatorname{MLD}_{\text {ex-RLL }}(\mathrm{P}=0.975)$. This could be explained by the naturally similar structures in blood distribution or lung tissue composition between the bilateral lower lobes since the MLD is related to gas content, gravity factors, blood distribution, and lung parenchymal proportion $(32,33)$. Second, the PMAD of these 2 lobes was low during inspiration and expiration, indicating the volumetric similarity of the bilateral lower lobes. In addition, from findings regarding ventilation workload during respiration, we verified that the bilateral lower lobes undertake more ventilation work than their respective volume ratio during respiration. This was shown in the $\lambda_{i n}$ of both lower lobes, which had risen when compared with $\lambda_{e x}$ (Figure 3). The consistency of bilateral lower lobes can also be explained by the anatomical structure of the lung, which is conical in shape with a narrow apex and a broad base, and the diaphragm and abdominal muscles mainly contribute to the breathing process (34). Furthermore, combined with the structure of the tracheobronchial tree, the air can be taken into and out of bilateral lower lobes more favorably under the abovementioned comprehensive conditions. This suggests that, when patients need to undergo a lobectomy or volume reduction therapy, more caution should be taken when the lesion is located in the lower lobes. Accordingly, segmentectomy or volume reduction may be used as alternative methods following consideration of whether the reduced pulmonary ventilation function will impact on the patient's quality of life.

For the lobar data analysis, we also found differences between the RML and the other lobes. The inspiratory and expiratory MLD of the RML were lower when compared with other lobes $\left[\mathrm{MLD}_{\text {in-RML }}:-873.15\right.$ (IQR, -884.33 to -860.38$) \mathrm{HU}, \mathrm{MLD}_{\text {ex-RML }}$ : -789.6 (IQR, -814 to -762.05) $\mathrm{HU}$, but these values did not reach the upper limit of emphysema $(-950 \mathrm{HU}$ for emphysema in inspiratory CT) and air trapping (-856 HU for air trapping in expiratory CT) (35). Mets et al. (23) also found this manifestation in healthy young men, indicating that the relatively low MLD (air-trapping-like change) of the RML is normal in the CT scan. The PMAD measurements showed that the RML had a larger difference in the volume ratio to other lobes than the differences between other lobes. Furthermore, we calculated the $\Delta \mathrm{LV}$ ratio and $\triangle M L D$ ratio of each lobe relative to its own inspiratory volume or MLD ( $\gamma_{\mathrm{LV}}$ and $\gamma_{\mathrm{MLD}}$; Table 4). The $\gamma_{\mathrm{LV}}$ and $\gamma_{\mathrm{MLD}}$ of the RML was also the lowest among the 5 lobes $\left[\gamma_{\mathrm{LV}}\right.$ RML: 0.36 (IQR, 0.28 to 0.44); $\gamma_{\text {MLD-RML }} 0.09$ (IQR, 0.07 to 0.12 ]), indicating that the RML experienced the least change during a respiration cycle. We speculate that this might be related to the anatomy of the RML, where the right main stem bronchus has a vertical orientation with the lower trachea, and the direction of the lower bronchus is the continuation of the right main bronchus. In addition, the contraction of the airway prevents the dispersion of airflow to maintain its axial direction momentum during respiration analyzed from the perspective of fluid dynamics $(36,37)$, hence smaller volume change ratio of RML, which was reflected by less change of the MLD. Through stepwise multivariable regression analysis, we found that factors such as height, gender, and age affected the inspiratory volume of each pulmonary part to varying degrees. Weight was the only factor related to volume of the RML which was distinguished from other lobes. The $M_{L} D_{\text {in-RML }}$ was only related to gender, while other lobes were mostly related to age. These findings demonstrated that the RML has special characteristics worthy of further investigation. 
Table 4 The LV and MLD change ratio $(\gamma)$ of each lobe

\begin{tabular}{lcc}
\hline Part of lung & $\gamma_{L V}$ & $\gamma_{M L D}$ \\
\hline TL & $0.51(0.46,0.58)$ & $0.17(0.13,0.2)$ \\
LL & $0.54(0.47,0.58)$ & $0.19(0.14,0.22)$ \\
RL & $0.49(0.45,0.56)$ & $0.16(0.13,0.19)$ \\
LUL & $0.49(0.4,0.55)$ & $0.15(0.1,0.17)$ \\
LLL & $0.58(0.54,0.63)$ & $0.24(0.19,0.28)$ \\
RUL & $0.46(0.39,0.54)$ & $0.13(0.1,0.18)$ \\
RML & $0.36(0.28,0.44)$ & $0.09(0.07,0.12)$ \\
RLL & $0.57(0.54,0.63)$ & $0.22(0.18,0.26)$ \\
\hline
\end{tabular}

$\gamma_{L V}$ indicates $\Delta L V / L V_{\text {in }}$ of each part; $\gamma_{M L D}$ indicates $\Delta M L D / M L D_{\text {in }}$ of each part. LV, lung volume; MLD, mean lung density; TL, total lung; $L L$, left lung; RL, right lung; LUL, left upper lobe; LLL, left lower lobe; RUL, right upper lobe; RML, right middle lobe; RLL, right lower lobe; $\Delta L V$, lung (or lobe) volume change during respiration; $\mathrm{LV}_{\text {in }}$, inspiratory lung (or lobe) volume; $\triangle \mathrm{MLD}$, mean lung (or lobe) density change during respiration; $M L D_{\text {in }}$, inspiratory mean lung (or lobe) density.

Previous studies have established the normal and abnormal LV and MLD range of the cohort at the TL level, and differences were identified between different races $(21,24,26)$. Since focal lesions may be overlooked when the lung function is evaluated at the TL level, the relationships between demographic data, LV, and MLD that we established could provide references for the normal values of $L V_{\text {in }}$ and $M L D_{\text {in }}$ in each lobe. Our study showed that age was a more important factor than other demographic information (gender, height, and weight) on MLD both at the TL and lobar level. This conflicts with observations in previous studies on lung density and age, which showed that the alveolar number growth ceases between 2 and 8 years of age, suggesting that an increase in age would not affect the MLD of normal lung parenchyma (32,38-41). However, Kalef-Ezra et al. (33) indicated that MLD decreases with age in men, while no age dependence was found in women. The reason for this difference may be related to the race, sample size, or CT imaging and reconstruction parameters. Further investigation was performed via multivariable regression analysis on expiratory LV and MLD (Table 5). For MLD, age was the main influencing factor whenever $M L D_{\text {ex }}$ was fitted to $M L D_{\text {in }}$ or vice versa, so the relationship between age and MLD is worth revisiting.

The limitations of this study were as follows: (I) an assumption of this study was that all lobes reach their maximum volume at the end of the inspiration phase and reach their minimum volume at the end of the expiration phase; however, some local regions may reach extreme volumes at different respiratory points, for example, the RUL reached its maximum volume at $80 \%$ of the inspiratory phase and its minimum volume at $20 \%$ expiratory phase (16). This limitation could be overcome if the 4DCT scans that track volumetric change of the entire breathing cycle are used for future analysis. (II) The evaluation of PFTs is affected by gender and age, but these cases were not grouped based on gender and age in our study due to the relatively small sample size. (III) This study only provided CT measurements of Chinese adults, but there are differences reported in lung capacity among people of different races $(24,42)$. Conversely, the differences and synergies among the lobes during respiration may be similar across different races. (IV) We were also not able to collect information about the smoking history of all the cases, while smoking may cause MLD to increase (43).

\section{Conclusions}

The LL undertakes a higher ventilation workload than its proportionate share. The 5 lung lobes were non-synchronous in breathing, but the bilateral lower lobes showed similarities and carried a high-ventilation function, while the volume and MLD of the RML had the least changes within a respiration cycle. This information could help to deepen the understanding of lung anatomy and provide baseline data for quantitative chest CT to be used in research and clinical practice related to different respiratory diseases. 
Table 5 Multivariate linear regression analyses of expiratory LV or MLD predicted by the inspiration

\begin{tabular}{|c|c|c|c|c|c|c|c|c|c|}
\hline $\begin{array}{l}\text { Dependent } \\
\text { variable }\end{array}$ & $\begin{array}{l}\text { Independent } \\
\text { variables }\end{array}$ & $\beta$ & std. error & $t$ & $P$ value & Linear regression equation & $R^{2}$ & Adjusted $\mathrm{R}^{2}$ & $F$ value \\
\hline \multicolumn{10}{|l|}{$\mathrm{LV}(\mathrm{mL})$} \\
\hline LVex-TL & $L V_{\text {in-TL }}$ & 0.257 & 0.072 & 3.582 & 0.001 & $\begin{array}{l}\mathrm{LV} \text { ex-TL }=-4,250.968+ \\
0.257^{\star} \mathrm{L} V_{\text {in }-\mathrm{TL}}+29.568^{\star} \text { Height }+ \\
10.263^{\star} \mathrm{Age}\end{array}$ & 0.566 & 0.546 & 28.67 \\
\hline \multirow[t]{2}{*}{ LVex-LL } & Constant & 134.544 & 104.904 & 1.283 & 0.204 & \multirow[t]{2}{*}{$L V_{\text {ex }-L L}=134.544+0.408^{\star} L V_{\text {in }-L L}$} & \multirow[t]{2}{*}{0.535} & \multirow[t]{2}{*}{0.529} & \multirow[t]{2}{*}{78.39} \\
\hline & $L V_{\text {in-LL }}$ & 0.408 & 0.046 & 8.854 & $<0.001$ & & & & \\
\hline LV ex-RL & Constant & $-2,408.937$ & 756.976 & -3.182 & 0.002 & $\begin{array}{l}\mathrm{LV} \text { ex-RL }=-2,408.937+ \\
0.233^{*} \mathrm{LV} \text { in-RL }+6.559^{*} \mathrm{Age}+ \\
16.942^{*} \text { Height }\end{array}$ & 0.544 & 0.523 & 26.23 \\
\hline \multirow[t]{3}{*}{ LVex-LUL } & Constant & -146.531 & 89.738 & -1.633 & 0.107 & \multirow{3}{*}{$\begin{array}{l}\text { LVex-LUL }=-146.531+0.558^{*} L_{\text {in }} \\
L U L+2.166^{*} \mathrm{Age}\end{array}$} & \multirow[t]{3}{*}{0.586} & \multirow[t]{3}{*}{0.574} & \multirow[t]{3}{*}{47.404} \\
\hline & LV in-LUL & 0.558 & 0.057 & 9.72 & $<0.001$ & & & & \\
\hline & Age & 2.166 & 1.035 & 2.093 & 0.04 & & & & \\
\hline \multirow[t]{2}{*}{ LVex-LLL } & Constant & 93.964 & 37.079 & 2.534 & 0.014 & \multirow[t]{2}{*}{$L V_{\text {ex-LLL }}=93.964+0.326^{*} L V_{\text {in-LLL }}$} & \multirow[t]{2}{*}{0.592} & \multirow[t]{2}{*}{0.586} & \multirow[t]{2}{*}{98.761} \\
\hline & LVin-LLL & 0.326 & 0.033 & 9.938 & $<0.001$ & & & & \\
\hline \multirow[t]{2}{*}{ LVex-RUL } & Constant & -141.425 & 70.122 & -2.017 & 0.048 & LVex-RUL $=-141.425+$ & 0.623 & 0.611 & 55.272 \\
\hline & LVin-RUL & 0.552 & 0.053 & 10.406 & $<0.001$ & & & & \\
\hline & $L V_{\text {in-RLL }}$ & 0.219 & 0.051 & 4.292 & $<0.001$ & $\begin{array}{l}0.219^{*} \mathrm{LV} \text { in-RLL }+5.434^{*} \text { Height }+ \\
1.644^{*} \mathrm{Age}\end{array}$ & & & \\
\hline & Height & 5.434 & 1.921 & 2.828 & 0.006 & & & & \\
\hline & Age & 1.644 & 0.82 & 2.004 & 0.049 & & & & \\
\hline MLD (HU) & & & & & & & & & \\
\hline MLDex-TL & Constant & 186.467 & 212.484 & 0.878 & 0.383 & MLDex-TL $=186.467+$ & 0.228 & 0.205 & 9.896 \\
\hline & MLDin-TL & 0.992 & 0.244 & 4.07 & $<0.001$ & $0.992^{*} M L D_{\text {in-TL }}-0.953^{\star} \mathrm{Age}$ & & & \\
\hline & Age & -0.953 & 0.398 & -2.395 & 0.019 & & & & \\
\hline MLD ex-LL & Constant & 265.685 & 219.68 & 1.209 & 0.231 & MLDex-LL $=265.685+$ & 0.23 & 0.207 & 10.005 \\
\hline & MLDin-LL & 1.073 & 0.251 & 4.272 & $<0.001$ & $1.073^{\star} M L D_{\text {in-LL }}-0.907^{\star}$ Age & & & \\
\hline & Age & -0.907 & 0.441 & -2.054 & 0.044 & & & & \\
\hline
\end{tabular}

Table 5 (continued) 
Table 5 (continued)

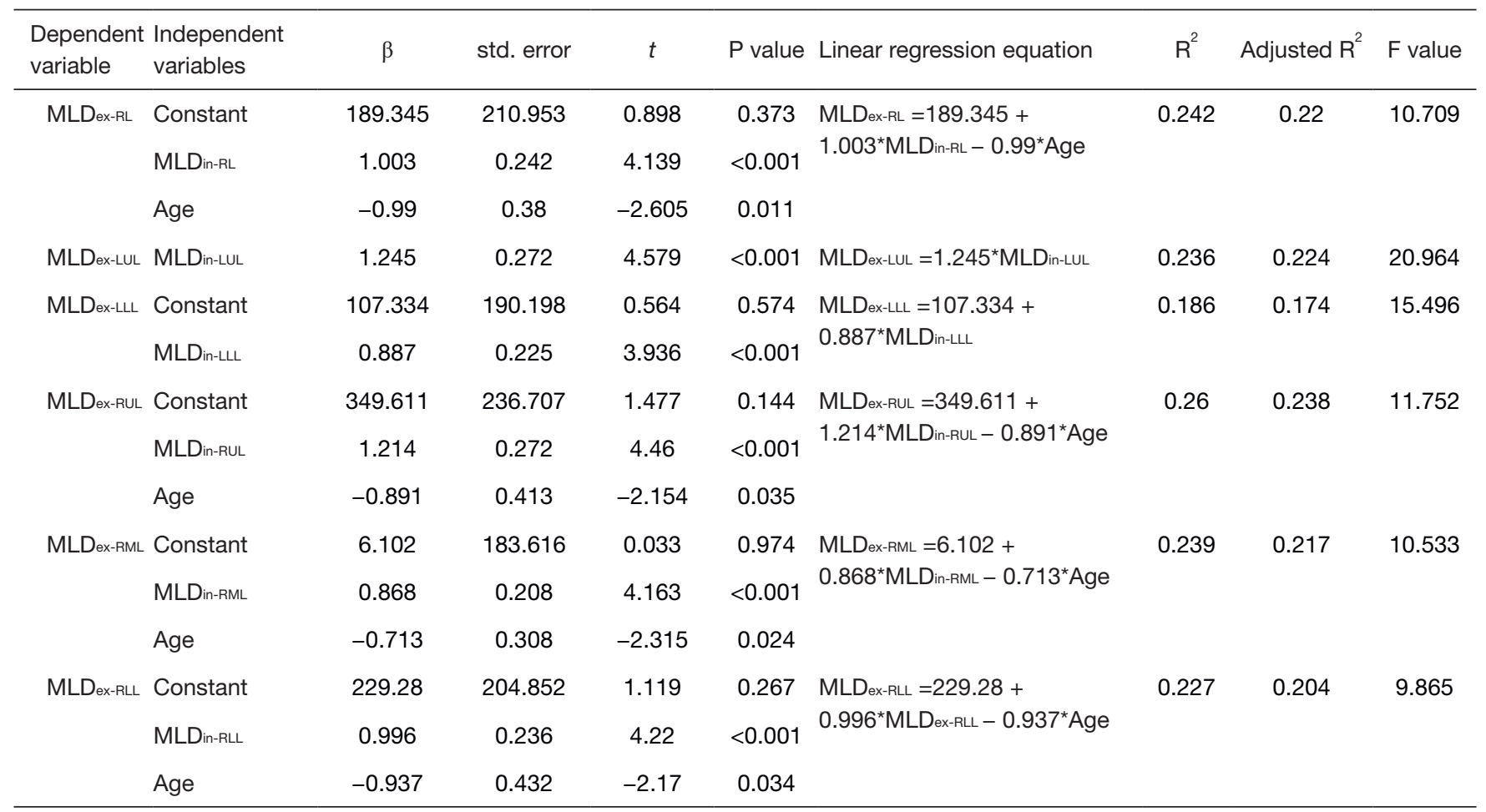

Stepwise multivariable linear regression analysis was used to explore the relationship between baseline demographic data (gender, age, height, and weight, for which gender was assigned as 1, male; 2, female) and the quantitative $C T$ results $\left(\operatorname{LV}_{\mathrm{ex}}, \mathrm{MLD}_{\mathrm{ex}}, \mathrm{LV}_{\text {in }}\right.$, and $\left.M L D_{\text {in }}\right)$, with an entry criterion of $\mathrm{P}<0.05$ and a removal criterion of $\mathrm{P}>0.10$. $\mathrm{P}<0.05$ were considered statistically significant. $\mathrm{LV}$, lung volume; MLD, mean lung density; $L_{\mathrm{ex}}$, lung volume in the expiratory phase; $T L$, total lung; $L V_{\text {in }}$, lung volume in the inspiratory phase; $L L$, left lung; $R L$, right lung; LUL, left upper lobe; LLL, left lower lobe; RUL, right upper lobe; RML, right middle lobe; RLL, right lower lobe; LLD $_{\text {ex }}$, mean lung density in the expiratory phase; $\mathrm{MLD}_{\text {in }}$, mean lung density in the inspiratory phase; $\mathrm{CT}$, computed tomography.

\section{Acknowledgments}

Funding: This study was supported by Key Research and Development Projects of Hubei Province (2020BAB022); the Huazhong University of Science and Technology COVID-19 Rapid Response Call (2020kfyXGYJ021) and National foundation of Science in China (11701201, 11871061 to CL; 11871262 to YZ).

\section{Footnote}

Conflicts of Interest: All authors have completed the ICMJE uniform disclosure form (available at https://dx.doi. org/10.21037/qims-21-348). JW was employed by Philips Healthcare. The other authors have no conflicts of interest to declare.

Ethical Statement: The authors are accountable for all aspects of the work in ensuring that questions related to the accuracy or integrity of any part of the work are appropriately investigated and resolved. The study was conducted in accordance with the Declaration of Helsinki (as revised in 2013). The Union Hospital, Tongji Medical College, Huazhong University of Science and Technology Institutional Review Board approved the study (No. 0271-01) and waived the informed consent for this retrospective analysis.

Open Access Statement: This is an Open Access article distributed in accordance with the Creative Commons Attribution-NonCommercial-NoDerivs 4.0 International License (CC BY-NC-ND 4.0), which permits the noncommercial replication and distribution of the article with the strict proviso that no changes or edits are made and the original work is properly cited (including links to both the formal publication through the relevant DOI and the license). 
See: https://creativecommons.org/licenses/by-nc-nd/4.0/.

\section{References}

1. Judge EP, Hughes JM, Egan JJ, Maguire M, Molloy EL, O'Dea S. Anatomy and bronchoscopy of the porcine lung. A model for translational respiratory medicine. Am J Respir Cell Mol Biol 2014;51:334-43.

2. Ford NL, Martin EL, Lewis JF, Veldhuizen RA, Drangova M, Holdsworth DW. In vivo characterization of lung morphology and function in anesthetized free-breathing mice using micro-computed tomography. J Appl Physiol (1985) 2007;102:2046-55.

3. Miller MR, Crapo R, Hankinson J, Brusasco V, Burgos F, Casaburi R, Coates A, Enright P, van der Grinten CP, Gustafsson P, Jensen R, Johnson DC, MacIntyre N, McKay R, Navajas D, Pedersen OF, Pellegrino R, Viegi G, Wanger J; ATS/ERS Task Force. General considerations for lung function testing. Eur Respir J 2005;26:153-61.

4. Miller MR, Hankinson J, Brusasco V, Burgos F, Casaburi R, Coates A, Crapo R, Enright P, van der Grinten CP, Gustafsson P, Jensen R, Johnson DC, MacIntyre N, McKay R, Navajas D, Pedersen OF, Pellegrino R, Viegi G, Wanger J; ATS/ERS Task Force. Standardisation of spirometry. Eur Respir J 2005;26:319-38.

5. Wanger J, Clausen JL, Coates A, Pedersen OF, Brusasco V, Burgos F, Casaburi R, Crapo R, Enright P, van der Grinten CP, Gustafsson P, Hankinson J, Jensen R, Johnson D, Macintyre N, McKay R, Miller MR, Navajas D, Pellegrino $\mathrm{R}$, Viegi G. Standardisation of the measurement of lung volumes. Eur Respir J 2005;26:511-22.

6. Pienn M, Burgard C, Payer C, Avian A, Urschler M, Stollberger R, Olschewski A, Olschewski H, Johnson T, Meinel FG, Bálint Z. Healthy Lung Vessel Morphology Derived From Thoracic Computed Tomography. Front Physiol 2018;9:346.

7. Hayashi K, Aziz A, Ashizawa K, Hayashi H, Nagaoki K, Otsuji H. Radiographic and CT appearances of the major fissures. Radiographics 2001;21:861-74.

8. Hersh CP, Washko GR, Estépar RS, Lutz S, Friedman PJ, Han MK, Hokanson JE, Judy PF, Lynch DA, Make BJ, Marchetti N, Newell JD Jr, Sciurba FC, Crapo JD, Silverman EK; COPDGene Investigators. Paired inspiratory-expiratory chest CT scans to assess for small airways disease in COPD. Respir Res 2013;14:42.

9. Nambu A, Zach J, Schroeder J, Jin G, Kim SS, Kim YI, Schnell C, Bowler R, Lynch DA. Quantitative computed tomography measurements to evaluate airway disease in chronic obstructive pulmonary disease: Relationship to physiological measurements, clinical index and visual assessment of airway disease. Eur J Radiol 2016;85:2144-51.

10. Usuba A, Yamashiro T, Handa H, Matsuoka S, Yamano Y, Mineshita M, Miyazawa T. Quantitative Computed Tomography Measurement of Tracheal Cross-Sectional Areas in Relapsing Polychondritis: Correlations with Spirometric Values. Respiration 2015;90:468-73.

11. Mets OM, Schmidt M, Buckens CF, Gondrie MJ, Isgum I, Oudkerk M, Vliegenthart R, de Koning HJ, van der Aalst CM, Prokop M, Lammers JW, Zanen P, Mohamed Hoesein FA, Mali WP, van Ginneken B, van Rikxoort EM, de Jong PA. Diagnosis of chronic obstructive pulmonary disease in lung cancer screening Computed Tomography scans: independent contribution of emphysema, air trapping and bronchial wall thickening. Respir Res 2013;14:59.

12. Shen M, Tenda ED, McNulty W, Garner J, Robbie H, Luzzi V, Aboelhassan AM, Van Geffen WH, Kemp SV, Ridge C, Devaraj A, Shah PL, Yang GZ. Quantitative Evaluation of Lobar Pulmonary Function of Emphysema Patients with Endobronchial Coils. Respiration 2019;98:70-81.

13. Matsuoka S, Kurihara Y, Yagihashi K, Hoshino M, Nakajima Y. Airway dimensions at inspiratory and expiratory multisection CT in chronic obstructive pulmonary disease: correlation with airflow limitation. Radiology 2008;248:1042-9.

14. Grillet F, Busse-Coté A, Calame P, Behr J, Delabrousse E, Aubry S. COVID-19 pneumonia: microvascular disease revealed on pulmonary dual-energy computed tomography angiography. Quant Imaging Med Surg 2020;10:1852-62.

15. Guerrero T, Sanders K, Noyola-Martinez J, Castillo E, Zhang Y, Tapia R, Guerra R, Borghero Y, Komaki R. Quantification of regional ventilation from treatment planning CT. Int J Radiat Oncol Biol Phys 2005;62:630-4.

16. Shao W, Patton TJ, Gerard SE, Pan Y, Reinhardt JM, Durumeric OC, Bayouth JE, Christensen GE. N-Phase Local Expansion Ratio for Characterizing Out-ofPhase Lung Ventilation. IEEE Trans Med Imaging 2020;39:2025-34.

17. Pulmonary Function and Clinical Respiratory Physiology Working Committee of Chinese Medical Doctor Association of Respiratory Physicians. Chinese pulmonary function test report specification. National Medical Journal of China 2019;99:1681-91. Available online: http:// rs.yiigle.com/CN112137201922/1150881.htm

18. Dietenbeck T, Alessandrini M, Barbosa D, D'hooge 
J, Friboulet D, Bernard O. Detection of the whole myocardium in 2D-echocardiography for multiple orientations using a geometrically constrained level-set. Med Image Anal 2012;16:386-401.

19. Comaniciu D, Zhou XS, Krishnan S. Robust real-time myocardial border tracking for echocardiography: an information fusion approach. IEEE Trans Med Imaging 2004;23:849-60.

20. Aslian H, Sadeghi M, Mahdavi SR, Babapour Mofrad F, Astarakee M, Khaledi N, Fadavi P. Magnetic resonance imaging-based target volume delineation in radiation therapy treatment planning for brain tumors using localized region-based active contour. Int J Radiat Oncol Biol Phys 2013;87:195-201.

21. Irion KL, Marchiori E, Hochhegger B, Porto Nda S, Moreira Jda S, Anselmi CE, Holemans JA, Irion PO. $\mathrm{CT}$ quantification of emphysema in young subjects with no recognizable chest disease. AJR Am J Roentgenol 2009;192:W90-6.

22. Zach JA, Newell JD Jr, Schroeder J, Murphy JR, CurranEverett D, Hoffman EA, Westgate PM, Han MK, Silverman EK, Crapo JD, Lynch DA; COPDGene Investigators. Quantitative computed tomography of the lungs and airways in healthy nonsmoking adults. Invest Radiol 2012;47:596-602.

23. Mets OM, van Hulst RA, Jacobs C, van Ginneken $\mathrm{B}$, de Jong PA. Normal range of emphysema and air trapping on CT in young men. AJR Am J Roentgenol 2012;199:336-40.

24. Kim SS, Jin GY, Li YZ, Lee JE, Shin HS. CT Quantification of Lungs and Airways in Normal Korean Subjects. Korean J Radiol 2017;18:739-48.

25. Nagatani Y, Murata K, Takahashi M, Nitta N, Nakano Y, Sonoda A, Otani H, Okabe H, Ogawa E. A new quantitative index of lobar air trapping in chronic obstructive pulmonary disease (COPD): comparison with conventional methods. Eur J Radiol 2015;84:963-74.

26. Cheng T, Li Y, Pang S, Wan H, Shi G, Cheng Q, Li Q, Pan Z, Huang S. Normal lung attenuation distribution and lung volume on computed tomography in a Chinese population. Int J Chron Obstruct Pulmon Dis 2019;14:1657-68.

27. Wang C, Xu J, Yang L, Xu Y, Zhang X, Bai C, et al. Prevalence and risk factors of chronic obstructive pulmonary disease in China (the China Pulmonary Health $[\mathrm{CPH}]$ study): a national cross-sectional study. Lancet 2018;391:1706-17.

28. Mendes LPS, Vieira DSR, Gabriel LS, Ribeiro-Samora
GA, Dornelas De Andrade A, Brandão DC, Goes MC, Fregonezi GAF, Britto RR, Parreira VF. Influence of posture, sex, and age on breathing pattern and chest wall motion in healthy subjects. Braz J Phys Ther 2020;24:240-8.

29. Simon BA. Non-invasive imaging of regional lung function using x-ray computed tomography. J Clin Monit Comput 2000;16:433-42.

30. Yamamoto T, Kabus S, von Berg J, Lorenz C, Keall PJ. Impact of four-dimensional computed tomography pulmonary ventilation imaging-based functional avoidance for lung cancer radiotherapy. Int J Radiat Oncol Biol Phys 2011;79:279-88.

31. Patton TJ, Gerard SE, Shao W, Christensen GE, Reinhardt JM, Bayouth JE. Quantifying ventilation change due to radiation therapy using 4DCT Jacobian calculations. Med Phys 2018;45:4483-92.

32. Robert HB, Robert AW, Kirk G, Drummond MB, Mitzner $W$. Lung density changes with growth and inflation. Chest 2015;148:995-1002.

33. Kalef-Ezra J, Karantanas A, Tsekeris P. CT measurement of lung density. Acta Radiol 1999;40:333-7.

34. Pilarski JQ, Leiter JC, Fregosi RF. Muscles of Breathing: Development, Function, and Patterns of Activation. Compr Physiol 2019;9:1025-80.

35. Schroeder JD, McKenzie AS, Zach JA, Wilson CG, Curran-Everett D, Stinson DS, Newell JD Jr, Lynch DA. Relationships between airflow obstruction and quantitative CT measurements of emphysema, air trapping, and airways in subjects with and without chronic obstructive pulmonary disease. AJR Am J Roentgenol 2013;201:W460-70.

36. Sul B, Oppito Z, Jayasekera S, Vanger B, Zeller A, Morris M, Ruppert K, Altes T, Rakesh V, Day S, Robinson R, Reifman J, Wallqvist A. Assessing Airflow Sensitivity to Healthy and Diseased Lung Conditions in a Computational Fluid Dynamics Model Validated In Vitro. J Biomech Eng 2018.

37. Sul B, Altes T, Ruppert K, Qing K, Hariprasad DS, Morris M, Reifman J, Wallqvist A. In vivo dynamics of the tracheal airway and its influences on respiratory airflows. J Biomech Eng 2019. [Epub ahead of print]. doi: $10.1115 / 1.4043723$.

38. Subramaniam K, Clark AR, Hoffman EA, Tawhai MH. Metrics of lung tissue heterogeneity depend on BMI but not age. J Appl Physiol (1985) 2018;125:328-39.

39. Gevenois PA, Scillia P, de Maertelaer V, Michils A, De Vuyst P, Yernault JC. The effects of age, sex, lung size, 
and hyperinflation on CT lung densitometry. AJR Am J Roentgenol 1996;167:1169-73.

40. Davies G, Reid L. Growth of the alveoli and pulmonary arteries in childhood. Thorax 1970;25:669-81.

41. Burri PH. Fetal and postnatal development of the lung. Annu Rev Physiol 1984;46:617-28.

42. Chan CC, Cheong TH, Poh SC, Wang YT. Lung elastic recoil in normal young adult Chinese compared with Caucasians. Eur Respir J 1995;8:446-9.

43. Remy-Jardin M, Edme JL, Boulenguez C, Remy J, Mastora I, Sobaszek A. Longitudinal follow-up study of smoker's lung with thin-section CT in correlation with pulmonary function tests. Radiology 2002;222:261-70.

Cite this article as: Wu F, Lin C, Chen L, Huang J, Fan W, Nie Z, Zhang Y, Li W, Wang J, Yang F, Zheng C. Asynchronous changes of normal lung lobes during respiration based on quantitative computed tomography (CT). Quant Imaging Med Surg 2022;12(3):2018-2034. doi: 10.21037/qims-21-348 